\title{
Introduction to the Handbook on Heritage, Sustainable Tourism and Digital Media
}

\author{
Silvia De Ascaniis and Lorenzo Cantoni
}

This Handbook takes into account the relations between heritage, tourism and digital media (or ICT, information and communication technology). While there are several publications that consider two of these three elements, very seldom are they examined under the same lens. To name just a few cases: heritage and tourism is the focus of Heritage, Tourism and Hospitality International Conference proceedings (see, e.g., Cantoni et al., 2020) and of recent manuscripts (Brooks, 2011; Timothy, 2011); heritage and digital media is the theme tackled by the EuroMed series (Ioannides et al., 2018; see also Cameron and Kenderdine, 2007; Rogerio-Candelera, 2014); tourism and digital media has been covered yearly since 1994 by the International Federation for IT and Travel and Tourism (IFITT) (Wörndl et al., 2021; see also Buhalis, 2003; Sheldon, 1997). There are a few books that look at the interplay of these three elements, focusing either on the economic aspects (e.g., Kaminski et al., 2013; Katsoni et al., 2017) or on the engineering and computing aspects (Rodrigues et al., 2017). This Handbook, instead, takes the perspective of communication, with the aim of increasing understanding of how digital media can be used to promote a sustainable relation between tourism and heritage.

\section{I.1 ON SUSTAINABILITY}

The focus here is not on the generic relation between tourism and heritage, but rather on a specifically qualified one, that is, a 'sustainable relation'. We need, thus, first to explain what is meant by 'sustainable'. As usual, etymology helps us to understand the meaning of words that we often use, as well as words that we often misuse. 'Sustainable' is a deverbal adjective formed by the verb 'sustain' and the suffix '-able', referring to the characteristic of a behaviour or a practice of being continued at a certain level. The verb 'sustain' comes from the Latin sustinere that is composed by the prefix 'sub-' (meaning 'under') and the verb tenere (meaning 'to hold'): to sustain means 'to hold from below', that is, to support. In the French language, the word for sustainable is durable, suggesting that the capacity of supporting should last over time (duration). The question this Handbook aims at contributing to answer is whether and how digital media can be used to promote a relation between tourism and heritage that can be supported and can be continued over time.

The issue of sustainability today is mostly discussed with reference to three domains of human experience and activity: environment, economy and society. Environmental sustainability refers to behaviours and practices that are respectful of the environment, limiting wastes and pollution, and making a balanced use of natural resources. Economical sustainability refers to the fact that related activities provide a (reasonable) profit, hence not needing to rely on external resources. Finally, in order for behaviours and practices to be accepted by local 


\section{Handbook on heritage, sustainable tourism and digital media}

communities or cultural groups, they have to be compliant with their values, habits and social norms, which means they should be socially and culturally sustainable.

Sustainability implies responsibility, and responsibility implies prudence, which is the virtue of considering the effects that choices or decisions made in the present time might have in the future. A behaviour or a practice can be sustained - that is, can be supported and continued over time - if it is responsible and prudent, which means that it does not have harmful consequences for those who are affected by it in the present as well as in the future.

Sustainability calls for a shift in the intentions behind human behaviours and social practices. If the perspective of possession and supremacy is taken, it creates imbalances at all levels: at a synchronous level in the consumption of natural resources, in the distribution of economic value, and when it comes to social justice among people; as well as at a vertical level, towards future generations. Environmental degradation, poverty and social inequality go together and have the same root: the desire to possess and to dominate nature and other human beings. On the other hand, if the perspective of cultivating and maintaining is taken, persons are seen as administrators of the goods, not masters. Administrators guarantee that each community takes whatever it needs for subsistence, but also that it fulfils its duty to protect the Earth and its inhabitants. Maintaining means caring, protecting, overseeing and preserving, it does not imply to make the Earth an object of worship, which would prevent us from working on it and protecting it in its fragility.

According to the considerations above, the issue this Handbook aims at addressing can be reformulated as follows: how can digital media be used to manage tourism so that natural and cultural heritage is preserved and can be of benefit for the common good? Some specific considerations on the three elements of this relation now follow.

\section{I.2 ON HERITAGE, TOURISM AND DIGITAL MEDIA}

Heritage is a living entity that is subject to the passing of time, to the changing of geographical, historical and social conditions, as well as to human action. It can be seen as a conversation between the past and the future. As a conversation, heritage is not given but taken, it is created and reshaped, not provided (Giaccardi, 2012). Many different actors (potentially, everyone) take part in this conversation: ancestors who created or shaped heritage, those who enjoy it today, and future generations who will inherit it. Heritage, then, can be considered a manifestation of the collective memory, of a family, of a social group or, in some cases, even of humankind. There are tangible and intangible goods that are of outstanding universal value from different points of view: from the historical, aesthetic, ethnological or anthropological, artistic points of view, from the points of view of science and conservation, or because of their natural beauty. In order to guarantee the preservation of the collective memory of humankind, so as to help keep the conversation open between the past and the future, the United Nations Educational, Scientific and Cultural Organization (UNESCO) has adopted two Conventions. The Convention Concerning the Protection of the World Cultural and Natural Heritage, adopted on 16 November 1972 and currently ratified by 194 state parties, and the Convention for the Safeguarding of the Intangible Cultural Heritage, adopted on 17 October 2003 and currently ratified by 179 state parties.

Cultural heritage refers in general to all the material traces that are significant to a community, a nation or/and humanity; it includes monuments (for example, architectural works, 
inscriptions, cave dwellings), groups of separate or connected buildings, sites and areas including archaeological sites. Natural heritage refers to natural features, geological and physiographical formations, and delineated natural areas that constitute the habitat of threatened species of animals and plants, and natural sites of value from the point of view of science, conservation or natural beauty (UNESCO, 1972).

Intangible heritage refers to "traditions or living expressions inherited from our ancestors and passed on to our descendants, such as oral traditions, performing arts, social practices, rituals, festive events, knowledge and practices concerning nature and the universe or the knowledge and skills to produce traditional crafts' (UNESCO, 2003).

Despite natural heritage constituting an important part of world heritage, the word 'heritage' is tightly bound to the word 'culture', stressing the dimension of time, as heritage is passed through time, and human intentional action, since heritage is passed from one generation to the other because it is considered worth sharing and protecting. A look into the etymology of the English word 'culture' can help to appreciate the richness and diversity of heritage. It comes from the Latin word cultŭra, which derives from the verb colere which means to look after, care. The verb can refer to the land or country, entailing the meaning of cultivating the soil (agriculture), and to human beings, indicating the nurturing and education of the human intellect and its skills (culture in the most common sense). Indeed, 'human cultural development is inexorably linked to the development of agriculture, because it is essentially the cultivation of nature, of the physical environment, which has historically shaped and engendered present-day landscapes' (UNESCO, 2013, p. 10). The past participle of the verb colere is cultus, which illustrates the act of worshipping God; in the English language, cultus is translated into the word 'cult'.

In its modern connotation, these different meanings are combined in the concept of culture: the methods employed to cultivate the soil developed over time according to the practices of different human communities; human intellect and skills need to be constantly cultivated with education and training in order to become civilized adults, exactly as plants need to be constantly nurtured to grow and bear fruit; the spiritual dimension deeply influences all the other aspects of human life. (Cantoni and De Ascaniis, 2016, p. 5)

These three meanings are also reflected in the variety of heritage sites and intangible traditions listed by UNESCO. Today, approximately 20 per cent of the properties have some sort of religious or spiritual connection and constitute the largest single category of World Heritage Sites (WHSs), ${ }^{1}$ while 13 per cent of WHSs have agricultural and/or pastoral characteristics. It should be noted, then, that agricultural landscapes are a subcategory of cultural landscapes, which are understood as the combined work of nature and man.

Agricultural landscapes, specifically, are those where cultivation of the land demonstrates a degree of uniqueness in comparison with other productive uses of soil, while pastoralism refers to breeding systems that use spontaneous plant resources for grazing, either on a farm or as part of transhumance or nomadism. 'Agricultural and agro-pastoral landscape expressions can also be taken into account within the framework of the Convention for the Safeguarding of Intangible Cultural Heritage as communities, practices and know-how that are shaping the landscape are important in developing practical cultivation or livestock' (Rössler and Tournoux in UNESCO, 2013, p. 13).

While so far we have referred mostly to UNESCO's Conventions, due to their global role, it should be stressed that heritage sites and heritage-related practices go well beyond those 


\section{Handbook on heritage, sustainable tourism and digital media}

listed by UNESCO: many more initiatives are running at local, regional, national and international levels. We should mention here at least one further major international initiative, by the Council of Europe: the Cultural Routes. ${ }^{2}$

The wish to enjoy cultural experiences is one of the main drivers of tourism. Visitors' essential motivation in cultural tourism is to learn, discover, experience and consume the tangible and intangible cultural attractions in a tourism destination (UNWTO, 2017). When the cultural motivation for tourism is linked to one's religious beliefs - such as visiting a place that is representative for one's own faith, a holy place - then we speak of a pilgrimage. Rural areas mostly devoted to agriculture and pastoralism, especially in recent decades, have also seen movements of people attracted by the possibility to enjoy and learn about agricultural-related activities; in this case, we speak of agri- or rural tourism (Figure I.1).

The responsible management of cultural and natural, tangible and intangible heritage is (or should be) part of sustainable tourism practices. Tourism can be a means to fight against poverty, because it provides employment, a means of peace and pacific coexistence, because it promotes encounters and mutual understanding. Sustainable tourism is not driven by consumerism or the yearning to collect many superficial experiences, but rather is able to foster encounters between people and territories, their growth in knowledge and mutual respect. If one visits a city, it is important not only that one knows which are its most important monuments, but also that one becomes aware of their history, and of how citizens live, of the challenges they face. If one climbs a mountain, besides respecting the natural terrain so as not to endanger one's own life, one should admire its beauty, respecting it and in this way creating a sort of bond with the natural elements, which is founded on knowledge and appreciation.

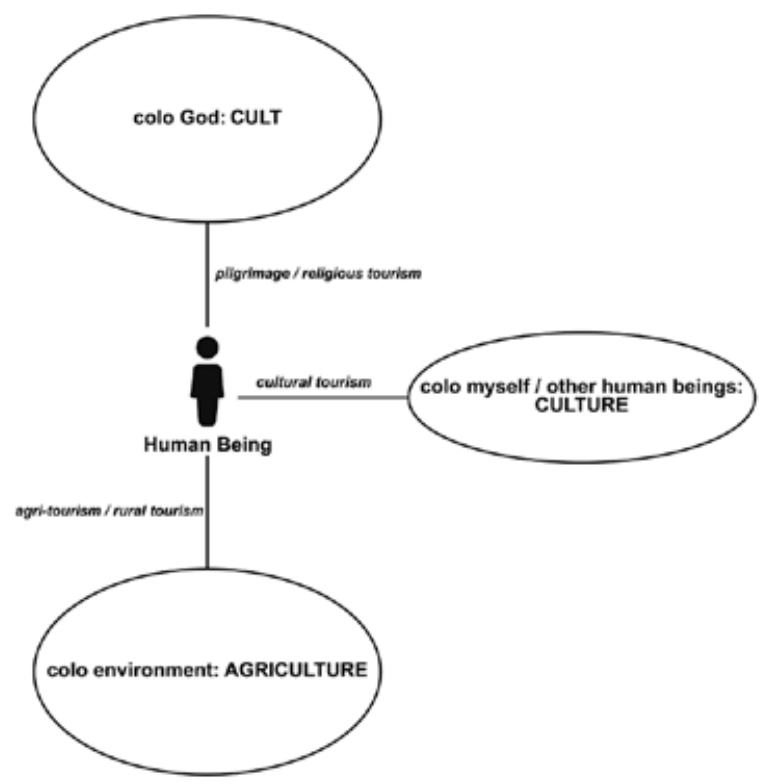

Source: Cantoni and De Ascaniis (2016, p. 5).

Figure I.1 Semantic scope of the Latin verb 'colere' 
If one takes part in a local ritual or buys an artifact of traditional craftsmanship one should acknowledge the specific values and beliefs attached to it.

If before the SARS-CoV-2 pandemic critical issues for sustainable tourism were overtourism and 'eat-and-go' tourism, now that freedom of movement is limited, sustainability is strictly related to maintaining behaviours that follow official protection provisions.

Digital media have enormously affected the way heritage is approached and presented, as well as the way tourism is conceived and practised. Given, then, the acceleration that the SARS-CoV-2 pandemic is causing to the digital transformation (Soto-Acosta, 2020), an ingenuous interpretation of digital media, namely one that reduces their impact, should be avoided. It is not enough to consider them just in terms of the singular tasks they allow to be performed faster and more efficiently; they should instead be seen as forces that go unnoticed while blended into our daily world. Digital media are able to deeply impact mental and relational habits, and not just to empower cognitive and operative functions. In our reality, it is even not meaningful to ask if one is online or offline. It is more appropriate to say that we are 'onlife', which is a buzzword introduced by some scholars to indicate the inextricable interweaving of life and the digital world (Floridi, 2015). Digital media can enlarge, to an excessive degree, gaps and inequalities in terms of wealth as well as knowledge. There is the risk that a few people know a lot about others, but these others do not know anything about those few people. Such asymmetry leads to wealth and knowledge being held in the hands of the few. On the other hand, digital media open up horizons and create possibilities in all domains that can improve people's quality of life incredibly.

This Handbook takes a positive approach to digital media yet one that does not reduce their impact, elaborating through several cases their role in promoting sustainable tourism at heritage sites, so as to increase awareness and participation into the conversation between the past and the future. The cases will be presented following a conceptual tool that we like to call the 'ABCDE framework' (Cantoni, 2020; De Ascaniis et al., 2018), which enables the mapping of such a rich field, and gives it a narrative structure.

\section{I.2.1 The ABCDE Framework}

The 'ABCDE' framework can be represented as a wheel. The circular shape of the wheel represents tourism at heritage sites. Digital media are at the centre of the representation, the hub. The five spokes connected to the hub represent the first five letters of the Latin alphabet and represent the main areas of intervention of digital media. Each spoke - letter - allows us to unpack and examine a specific facet of the contribution that digital media can make to sustainable tourism at heritage sites. While stressing one facet, a specific form of digital media can contribute in more than one way: it can enlarge 'Access' to information about a heritage destination; it can make the tourism experience 'Better'; it can 'Connect' residents, visitors and heritage; it can 'Disintermediate' (some) relationships; it can 'Educate' players in the field. Each type of contribution is now discussed further.

\section{Access}

Digital media can enlarge access: on the one hand, providing more (multimedia) information about heritage places for inspiration and information gathering; on the other hand, supporting all the planning phases of those who want to visit them. The structural characteristics of the electronic text allow multiple and extremely varied affordances, especially when it comes to 


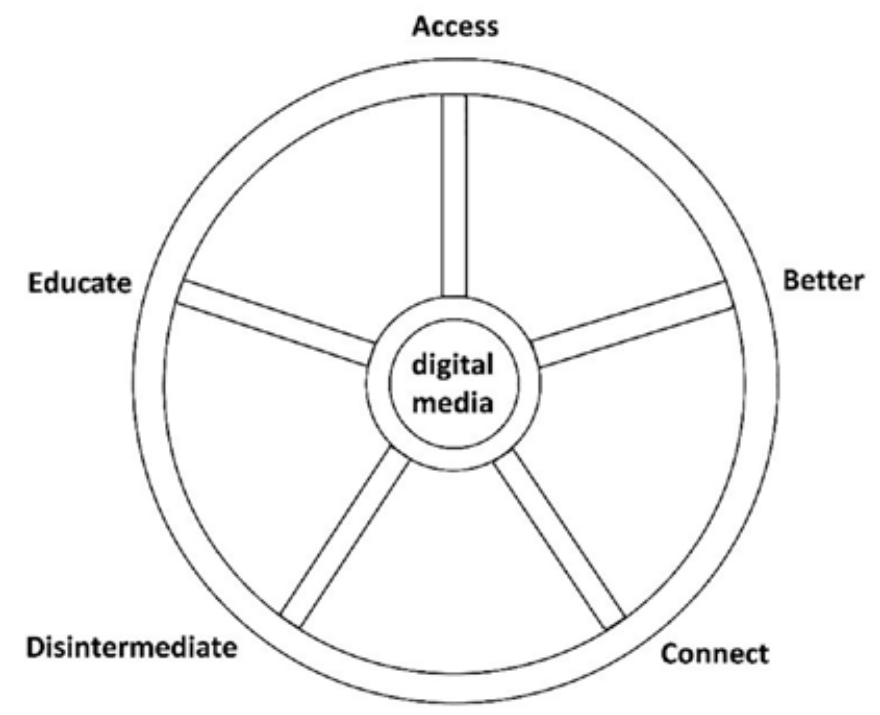

Figure I.2 ABCDE framework: main areas of intervention of digital media in sustainable tourism at heritage destinations

covering the two information-intensive fields of tourism and culture. However, the increase in availability to information makes the issue of information quality ever more more critical. Due to the borderless accessibility of digital information, its suitability for different publics with (very) different linguistic and cultural backgrounds has to be tackled and discussed. It is a growing trend among destination management organizations to address different audiences that is, prospective travellers - not just by translating information into different languages, but also through cultural localization of their online communication channels. Culturally localized information is able to engage readers because it is perceived as close to their understanding, habits and beliefs. An example of a successfully localized digital tool is the website of Switzerland Tourism, ${ }^{3}$ with 16 versions addressed to 16 different markets which differ not just in terms of language, but also in terms of images and other multimedia contents, narratives, promoted products and services, content structure and layout.

\section{Better}

Once visitors have reached a heritage destination, eTourism-related services can make their experiences better. Making experiences better means providing additional value, in terms of either content or form.

On the one hand, digital media can add value to experiences at heritage sites in terms of knowledge provision providing representations of site-related features. An extraordinary improvement in the provision of on-site online services and information has been brought about by location-based services (LBS), which are software services that utilize the geographical location of users to gather data and provide tailored information. They have been made possible by technological developments such as the World Wide Web, the Global Positioning System (GPS) and the widespread use of smartphones. LBS are critical to many businesses as well as government organizations, and can enhance experiences in a variety of contexts, from 
health to entertainment, from work to tourism, and so on. Examples of LBS include navigation software, tracking systems, location-based advertising, personalized weather services and location-based games.

LBS are the base of most of augmented reality (AR) technologies, which are digital applications able to add layers of information or additional possibilities when interacting with an object. AR is an extension of affordances given by any technology. Think, for instance, of the thermometer, which enables measuring the temperature of a human being or of a location; information that would not be easy to know otherwise. The dimension of 'Better' is deeply bound to the dimension of 'Access'. Great opportunities are opened for tourism both at heritage sites by augmented reality applications, which can enrich the visit and make it more exciting; and online, by offering to tourists the possibility of a virtual visit (thanks to virtual reality applications) of sites or parts of sites that no longer exist. The augmented reality application for Cluny Abbey is an example of this. Cluny Abbey used to be the largest church in Christendom before the construction of St Peter's Basilica in Rome but was almost completely destroyed after the French Revolution. The app offers the visitors the possibility to get a sense of how the church looked in the past. ${ }^{4}$

On the other hand, digital media open original ways of creating new experiences by combining entertainment with learning and awareness goals. Gamification is a practice that goes in this direction. It means applying game-design principles in non-gaming contexts to reach 'serious' goals such as educating people about sustainable behaviour, increasing awareness about a social problem or, in our case, about the value of heritage. An example of gamified mobile application that aims at enhancing the experience at WHSs while fostering learning is 'DW World Heritage 360'.5 While enjoying a 360-degree view of three WHSs in Germany, the user is challenged with searching for clues to solve puzzles and find secret pathways, and is told stories about the site.

In the digital world, every action that is performed online leaves a trace, a digital footprint that can be stored and analysed. The so-called 'big data' are collections of digital footprints in a domain or about certain activities, which might reveal trends, social habits and collective behaviours, and thus might be used to improve the quality of life in different domains. In the field of tourism, such data can reveal tourism dynamics at specific places and suggest improvements in the management and offering of services. This has led to the creation of the concept of 'smart destinations', which are destinations where tourism suppliers, local administrations and visitors interplay in order to perform three main activities: (1) collect data about the destination coming from many different sources; (2) analyse such data and develop algorithms to forecast tourism behaviours and improve services; and (3) implement economic, financial and territorial development measures aimed at making the destination more efficient, more sustainable and more appealing to tourists and locals. Big data, then, constitute immeasurable sources of personal information about needs and preferences of consumers - here, tourists - which if combined with appropriate digital tools allow the customization or even the personalization of offers. Location-based data can be combined with users' personal information to elaborate recommendations: this is the case of personalized ads on social media accounts, for restaurants, events or attractions in the destination that one is visiting. While acknowledging the great opportunities offered by data availability and analysis, we need to stress here the connected issue of privacy: travellers should be granted full control of the data they generate; heritage and tourism players should use them with full respect for privacy. 


\section{Connect}

Digital media are connection technologies par excellence. When information is shared, the sender and the receiver become closer to one another, thanks to what they are sharing. The very term 'communication' - which is found in the term 'information and communication technologies' that is often used as a synonym for digital media - comes from the ancient Latin, and means to share a value (cum = together + munus $=$ value $)$. When it comes to tourism at heritage sites, digital media can facilitate the connection between residents and their heritage, residents and visitors, visitors and heritage. While allowing the transfer and sharing of information in the form of digital content, in an increasingly vast amount and variety of (converged) media and at an increasing speed, digital media can offer paths to deeper meaning and turn phenomena into experiences. They can leverage the power of heritage interpretation and storytelling, promoting the understanding and preservation of heritage as well as supporting destination marketing (Tilkin, 2014). Different digital media can be employed in different phases of heritage interpretation, and can enhance storytelling activities both because they help to tell stories in a more impactful way, and because they give destination management organizations (DMOs) and heritage sites and organizations tools to overcome the fragmentation of the many and diverse information about what a destination has to offer.

Web 2.0 and social media, then, have allowed incredible opportunities to connect tourists, residents and heritage, because they are able to remove the 'walls between the special and the everyday, between academic disciplines, between the expert and the lay, between past and future, between "us" and "others"' (Fairclough, in Giaccardi, 2012, p. xvi).

A case representing a perfect combination of a strategic use of social media, and a thorough promotion of an original narrative, is the initiative \#faces4heritage, launched in support of the UNESCO global campaign \#Unite4Heritage in 2015. \#faces4heritage was designed in response to the attacks on heritage sites by violent extremists, with the aim of promoting and protecting the world's cultural heritage diversity. An alternative narrative was developed in contrast to extremists' violent messages, which showed the horrible consequences of their actions and conveyed an alternative point of view, one that stressed the universal value of heritage and the need to preserve it for future generations. A massive campaign on social media was implemented which received the endorsements of important public institutions in the fields of tourism and heritage, among which were UNESCO, the European Travel Commission and embassies (see www.faces4heritage.org, and its channels on Twitter and Facebook).

\section{Disintermediate}

One of the key transformations prompted by digital media in the travel and tourism industry is disintermediation, which refers to the possibility (and ability) of suppliers to communicate directly with consumers, shifting the power away from intermediaries. This is mainly due to the easy and direct access to information by both the demand and the supply side, and digital media has become a major source of competitiveness for both industry and destinations. In some cases, though, physical intermediaries have simply been shifted to online equivalents, often referred to as 'cybermediaries'. This is the case for Airbnb, an online platform that puts in contact people looking for an accommodation for a short time and people who have accommodation to rent. It acts as a broker, receiving commissions from each booking, and also as a reputation builder, because consumers can leave reviews about their accommodation experience and hosts can rate guests. In other cases, we are witnessing a re-intermediation process 
of travel and hospitality services that is the addition of new types of intermediaries. It is the case of online travel agencies such as Expedia.com and Booking.com, which are among the largest players today in the online travel and hospitality industry. Re-intermediation processes, however, risk concentrating power in even less hands than before the internet, because they imply infrastructural information technology (IT) resources as well as IT human resources, which might not be available to small and medium-sized enterprises. Nowadays, this process appears to be led by Google, which might eventually become the main (and possibly the only) online travel agency.

Cultural and heritage tourism enterprises are mostly small or micro in nature, and generally rely on intermediaries to attract the market. Smart management of digital media for these enterprises is, thus, of the utmost importance, to exploit the opportunities they afford of enhancing capacities in key areas such as operations, marketing, management and communication with visitors. In this way, more money could reach the local communities, instead of remaining in the hands of intermediating tour operating players.

A leading role in the disintermediation process is played by social media. With the rise in social media, it appears that communication has been democratized, in the sense that it is no longer a domain for experts or professionals - that is, those in marketing, journalism and public relations - but a tool used by any person or community equipped with an internet connection to voice their opinions and to participate in public discourses. Word-of-mouth represents one of the most influential sources of information when making a variety of decisions, thanks to its ease of access and multiplicity of contributors. Prospective tourists, in particular, face several challenges when making travel decisions - for example, what destinations to visit, where to stay, activities and attractions to enjoy, what carriers to use - because of the very nature of tourism, which is experiential, with intangible and perishable goods, and because of the extraordinary variety of available options. The testimony of others thus plays a key role in risk and uncertainty reduction in travel decision-making (De Ascaniis and Gretzel, 2013). Online travel reviews are among the most accessible and prevalent form of electronic word-of-mouth in the field of tourism, and represent people's wish to share their travel experiences online, recommend a tourism product/service or complain about it (De Ascaniis et al., 2015). The contribution of online travel reviews to tourism at heritage sites is manifold, and can be linked to different facets of the ABCDE framework; they can enlarge access to first-hand information about a site or intangible heritage, and connect visitors with heritage and also residents with their heritage; they can disintermediate the relation between visitors and tourism suppliers and destination managers, allowing suppliers and managers to identify critical aspects to be improved or aspects on which to focus for an effective promotion of the place.

\section{Educate}

The field of tourism is in constant and dynamic evolution and is characterized by high turnover, seasonality, and micro, small and medium-sized enterprises. In such an environment, enterprises need updated sets of skills to engage with tourism trends and demands, and only a small percentage of operators can attend regular and extensive training courses. Digital media can be extensively used to support tourism operators' training and lifelong learning, thanks to the flexibility offered by eLearning in terms of space and time, as well as in terms of costs. eLearning relies on the characteristics of interactivity and connectivity of the web, involving students or employees from different countries, faculties and industries, interacting with educational materials online, as well as engaging with tutors and peers in dynamic ways. 
Digital media integration in tourism and cultural heritage can have a positive effect on education at a global scale (Murphy et al., 2017; Sigala, 2012).

Ad hoc eLearning interventions can be designed by the main players in the field of tourism and heritage, that is: academic institutions, destination management organizations, international umbrella institutions, cultural heritage organizations, non-governmental organizations and individual providers. Some programmes, then, might be suitable for different stakeholders with different levels of education and professional experience, upon adaptation or selection of available materials. A current growing trend are the massive open online courses (MOOCs) that are accessible to anyone, without formal entry requirements. The MOOC 'eTourism: Communication Perspectives', for instance, was the first to be devoted to this topic, and has attracted in its first edition 5500+ learners, 31 per cent of them have been active, while 7.1 per cent have completed the course and got a participation certificate. Half of them were full-time workers, who could not have attended regular courses on the topic (Lin et al., 2018). The second edition of this MOOC, offered also in Chinese, Spanish and Italian, is still available online. ${ }^{6}$

eLearning has proved to be an indispensable resource to support the resilience of tourism during the coronavirus crisis. According to the UNWTO:

This pandemic affects every level of society and we [tourism operators] stand by those affected in these times. The impact of the pandemic on already slowing economies has made tourism particularly vulnerable, becoming the hardest hit sector so far. With $80 \%$ of the sector made up of small and medium-sized enterprises, millions of livelihoods in the world are left vulnerable. ${ }^{7}$

UNESCO has launched its Global Education Coalition, as a Covid-19 Education Response: \#LearningNeverStops. Among the several initiatives launched around the world was 'eLearning for Tourism during the time of Coronavirus', ${ }^{8}$ promoted by USI - Università della Svizzera italiana. Its goal was to reach out to tourism players with helpful tools to boost their resilience; to do so, many educational resources were updated and/or made available for free.

In this Handbook several cases of digital media for tourism at heritage sites are presented, which will allow the reader to consider further our discussion of the topic so far. Cases have been grouped according to the facet of the ABCDE framework they contribute to the most. Each one of the five parts of the book is introduced by an overview chapter, where the main aspects of each letter of the framework are discussed.

We hope that this Handbook might contribute to increase awareness of the great opportunities that digital media give to tourists, residents and tourism players when it comes to discovering and experiencing the beauty and richness of heritage, as well as to inspire actions that might help to keep the conversation with the past open and sustain the future.

\section{NOTES}

1. http://whc.unesco.org/en/religious-sacred-heritage/ (accessed: 20 December 2020).

2. https://www.coe.int/en/web/cultural-routes.

3. https://www.myswitzerland.com/en-ch.

4. www.clunypedia.com.

5. Available at: https://play.google.com/store/apps/details?id=io.viond.deutschewelle\&hl=en_US\&gl $=$ US. 
6. www.eTourismMOOC.ch.

7. https://www.unwto.org/news/covid-19-statement-zurab-pololikashvili.

8. https://www.unescochair.usi.ch/elearning-for-tourism-in-the-time-of-coronavirus.

\section{REFERENCES}

Brooks, Graham (2011), Communicating Heritage: A Handbook for the Tourism Sector, Madrid: World Tourism Organization (WTO).

Buhalis, Dimitrios (2003), eTourism: Information Technology for Strategic Tourism Management, London: Pearson Education.

Cameron, Fiona and Kenderdine, Sara (2007), Theorizing Digital Cultural Heritage: A Critical Discourse, Cambridge, MA: MIT Press.

Cantoni, Lorenzo (2020), 'Digital transformation, tourism and cultural heritage', in Maria Gravari-Barbas (ed.), A Research Agenda for Heritage Tourism, Cheltenham, UK and Northampton, MA, USA: Edward Elgar Publishing. DOI: https://doi.org/10.4337/9781789903522.00025.

Cantoni, L. and De Ascaniis, S. (2016), 'Pilgrims in the Digital Age: a research manifesto', International Journal of Religious Tourism and Pilgrimage, 4 (3), 1-5.

Cantoni, Lorenzo, De Ascaniis, Silvia and Elgin-Nijhuis, Karin (eds) (2020), Living Heritage and Sustainable Tourism, Lugano: Università della Svizzera italiana.

De Ascaniis, Silvia, Borrè, Alessia, Marchiori, Elena and Cantoni, Lorenzo (2015), 'Listen to your customers. How hotels manage online travel reviews: the case of hotels in Lugano', in Iis Tussyadiah and Alessandro Inversini (eds), Information and Communication Technologies in Tourism 2015, Cham: Springer, pp. 59-72.

De Ascaniis, Silvia, Gravari-Barbas, Maria and Cantoni, Lorenzo (2018), Tourism Management at UNESCO World Heritage Sites, Lugano: Università della Svizzera italiana. Available at: http://doc .rero.ch/record/309527.

De Ascaniis, S. and Gretzel, U. (2013), 'Communicative functions of online travel review titles: a pragmatic and linguistic investigation of destination and attraction OTR titles', Studies in Communication Sciences, 13 (2), 156-165.

Floridi, Luciano (ed.) (2015), The Onlife Manifesto: Being Human in a Hyperconnected Era, London: Springer Nature.

Giaccardi, Elisa (ed.) (2012), Heritage and Social Media: Understanding Heritage in a Participatory Culture, London: Routledge.

Ioannides, Marinos, Fink, Eleanor, Brumana, Raffaella, Patias, Petros, Doulamis, Anastasios, et al. (eds) (2018), Digital Heritage. Progress in Cultural Heritage: Documentation, Preservation, and Protection, Proceedings of EuroMed 2018, Cham: Springer.

Kaminski, Jamie, Benson, Angela M. and Arnold, David D. (eds) (2013), Contemporary Issues in Cultural Heritage Tourism, London: Routledge.

Katsoni, Vicky, Upadhya, Amitabh and Stratigea, Anastasia (2017), Tourism, Culture and Heritage in a Smart Economy, Cham: Springer.

Lin, J., Cantoni, L. and Murphy, J. (2018), 'MOOCs in tourism and hospitality: a review', Journal of Teaching in Travel and Tourism, 18 (3), 217-235.

Murphy, Jamie, Kalbaska, Nadzeya, Cantoni, Lorenzo, Horton-Tognazzini, Laurel, Ryan, Peter and Williams, Alan (2017), 'Massive open online courses (MOOCs) in tourism', in Pierre Benckendorff and Anita Zehrer (eds), Handbook of Teaching and Learning in Tourism, Cheltenham, UK and Northampton, MA, USA: Edward Elgar Publishing, pp. 154-172.

Rodrigues, João M.F., Ramos, Célia M.Q., Cardoso, Pedro J.S. and Henriques, Cláudia (eds) (2017), Handbook of Research on Technological Developments for Cultural Heritage and eTourism Applications, Hershey, PA: IGI Global.

Rogerio-Candelera, Miguel Ángel (eds) (2014), Science, Technology and Cultural Heritage, Boca Raton, CA: CRC Press. 


\section{Handbook on heritage, sustainable tourism and digital media}

Sheldon, Pauline J. (1997), 'Tourism information technology', in Henry Dwyer and Peter Forsyth (eds), International Handbook on the Economics of Tourism, Cheltenham, UK and Northampton, MA, USA: Edward Elgar Publishing, pp. 399-418.

Sigala, Marianna (2012), 'Investigating the role and impact of geovisualisation and geocollaborative portals on collaborative e-learning in tourism education', Journal of Hospitality, Leisure, Sport and Tourism Education, 11 (1), 50-66.

Soto-Acosta, P. (2020), 'COVID-19 pandemic: shifting digital transformation to a high-speed gear', Information Systems Management, 37 (4), 260-266.

Tilkin, Guy (2014), 'InHerit. Professional development in heritage interpretation', Manual, Alden Biesen, Bilzen, accessed 2 October 2020 at http://ictop.org/wp-content/uploads/2017/01/Manual -InHerit-EN.pdf.

Timothy, Dallen, J. (2011), Cultural Heritage and Tourism: An Introduction, Vol. 4, Bristol: Channel View Publications.

UNESCO (1972), 'Convention Concerning the Protection of the World Cultural and Natural Heritage', accessed 30 September 2020 at https://whc.unesco.org/en/conventiontext/.

UNESCO (2003), 'Convention for the Safeguarding of the Intangible Cultural Heritage', accessed 30 September 2020 at https://ich.unesco.org/en/convention.

World Heritage Centre (2013), 'World Heritage Agricultural Landscapes', 69, UNESCO, https://whc .unesco.org/en/review/69/.

Wörndl, Wolfgang, Koo, Chulmo and Stienmetz, Jason L. (eds) (2021), Information and Communication Technologies in Tourism 2021, Cham: Springer.

UNWTO (2017), 'Chengdu Declaration on "Tourism and the Sustainable Development Goals", 22nd Session of the General Assembly held in Chengdu, China (11-16 September), accessed 30 October 2020 at https://www.e-unwto.org/doi/epdf/10.18111/unwtogad.2017.1.g51w645001604506. 